\title{
Non-anaemic iron deficiency
}

\section{SUMMARY}

Iron deficiency without anaemia is common. Patients may present with unexplained, non-specific symptoms.

Iron studies will usually show a low ferritin and low transferrin saturation with a normal haemoglobin concentration. The cause of the iron deficiency should be identified and managed.

There is limited evidence about the benefits of giving iron to people who do not have anaemia. If there is iron deficiency, most people can be given oral iron supplements.

Iron studies are repeated after 60-90 days of oral iron supplements. Further investigations are needed if the iron deficiency has not been corrected.

Some patients, including those who have not responsed to oral supplements may benefit from intravenous iron. There is no role for intramuscular injections of iron.

\section{Introduction}

Iron deficiency is the most common mineral deficiency and iron deficiency anaemia affects approximately $20 \%$ of the world's population. Iron deficiency without anaemia is even more common.' It is an important public health problem in Australia. The World Health Organization (WHO) estimates that $8 \%$ of preschool children, $12 \%$ of pregnant women and $15 \%$ of non-pregnant women of reproductive age in Australia have anaemia, with iron deficiency being the major cause. ${ }^{2}$ Anaemia is highly prevalent in indigenous communities. A study of an Aboriginal community in Western Australia identified anaemia among 55\% of women and $18 \%$ of men. ${ }^{3}$ Although it is three times as common as iron deficiency anaemia, iron deficiency without anaemia is an under-recognised and undertreated condition. ${ }^{4}$

\section{Iron deficiency}

Approximately $70 \%$ of the iron in adults is found within haemoglobin in red blood cells so anaemia is the most readily recognised effect of iron deficiency. However, it is now apparent that iron deficiency in the absence of anaemia also has unfavourable consequences.

While there is extensive literature surrounding iron deficiency anaemia, there is a paucity of evidence in non-anaemic iron deficiency. The current literature is predominantly based on small studies with often heterogeneous populations. As a result, there are no firm pathways to guide investigations, treatment and monitoring.

\section{Presenting problems}

Iron is an essential element, required for several metabolic pathways and responsible for the delivery of oxygen to organs and body tissues. A deficiency can therefore result in a wide range of symptoms that are non-specific and may not be initially recognised as being due to iron deficiency.

Iron deficiency without anaemia has been associated with:

- weakness, fatigue, reduced exercise performance, difficulty in concentrating, and poor work productivity 5

- neurocognitive dysfunction including irritability ${ }^{6}$

- fibromyalgia syndrome ${ }^{7}$

- $\quad$ symptom persistence in patients treated for hypothyroidism $^{9}$

- poor neurodevelopmental outcomes in infants born to mothers with iron deficiency. ${ }^{10}$

\section{Diagnosing iron deficiency}

Iron deficiency can occur secondary to inadequate dietary intake, increased requirements (e.g. pregnancy and breastfeeding), impaired absorption (e.g. coeliac disease, bariatric surgery), or blood loss (e.g. menstrual, blood donation, gastrointestinal). A drug history should be taken particularly regarding anticoagulants, over-thecounter non-steroidal anti-inflammatory drugs and antiplatelet drugs. The underlying cause of iron deficiency should always be sought and managed.
- $\quad$ restless legs syndrome ${ }^{8}$

\section{Shalini Balendran}

Haematology advanced trainee, Westmead Hospital, Sydney

\section{Cecily Forsyth}

Haematologist, Central Coast Haematology, Gosford, New South Wales

\section{Keywords}

dietary iron, ferritin, iron deficiency, iron supplements, transferrin

Aust Prescr 2021:44:193-6 https://doi.org/10.18773/ austprescr.2021.052 


\section{Table 1 Iron studies in the differential diagnosis of iron deficiency}

\begin{tabular}{lllll}
\hline Test & $\begin{array}{l}\text { Iron deficiency } \\
\text { without anaemia }\end{array}$ & $\begin{array}{l}\text { Iron deficiency } \\
\text { anaemia }\end{array}$ & $\begin{array}{l}\text { Anaemia of chronic } \\
\text { disease }\end{array}$ & $\begin{array}{l}\text { Iron deficiency anaemia and } \\
\text { anaemia of chronic disease }\end{array}$ \\
\hline Haemoglobin & $N$ & $\downarrow$ & $\downarrow$ & $\downarrow$ \\
\hline Mean cell volume & $\mathrm{N}$ or $\downarrow$ & $\downarrow$ & $\mathrm{N}$ (or mildly $\downarrow$ or & $\downarrow$ \\
\hline Serum ferritin & $\downarrow$ & $\downarrow$ & $\downarrow$ or $\mathrm{N}$ & $\mathrm{N}$ or $\uparrow$ \\
\hline Total iron-binding capacity & $\mathrm{N}$ or $\uparrow$ & $\uparrow$ & $\downarrow$ or $\mathrm{N}$ & $\downarrow$ \\
\hline Transferrin saturation & $\downarrow$ or $\mathrm{N}$ & $\downarrow$ & $\mathrm{N}$ & $\uparrow$ \\
\hline Soluble transferrin receptor & $\mathrm{N}$ or $\uparrow$ & $\uparrow$ &
\end{tabular}

$\mathrm{N}=$ normal, $\downarrow=$ decreased, $\uparrow=$ increased

Iron studies assist in the differential diagnosis of iron deficiency (Table 1). A reduced ferritin is the most reliable initial marker to diagnose iron deficiency without anaemia. Although WHO defines low serum ferritin as less than 12 microgram/L in adults, a concentration of less than 30 microgram/L has a high sensitivity (92\%) and specificity (98\%) for iron deficiency, ${ }^{11}$ correlating with the absence of iron stores in the bone marrow (see Table 2). Changes in iron status before the development of anaemia may be suggested on a full blood count by falling values for mean cell haemoglobin and mean corpuscular volume and an increased red cell distribution width.

Ferritin is an acute-phase protein so it rises in inflammatory conditions and in the elderly. This can make the diagnosis of iron deficiency challenging. In these cases, a higher ferritin threshold (<100 microgram/L) with a low transferrin saturation (<20\%) can be used. To diagnose iron deficiency in patients with heart failure, the European Society of Cardiology has recommended a ferritin concentration below 100 microgram/L,

\section{Table 2 Ferritin and transferrin thresholds for the diagnosis of iron deficiency}

\begin{tabular}{lll}
\hline Patients and conditions & Ferritin concentration & Transferrin saturation \\
\hline General population & $<30$ microgram $/ \mathrm{L}$ & - \\
\hline Inflammatory states & $<100$ microgram $/ \mathrm{L}$ & $<20 \%$ \\
\hline Heart failure & $<100$ microgram $/ \mathrm{L}$ & - \\
\hline Kidney disease & $<300$ microgram $/ \mathrm{L}$ & $<20 \%$ \\
\hline
\end{tabular}

or below 300 microgram/L with a transferrin saturation below $20 \% .^{12}$ In chronic kidney disease, the Kidney Disease Improving Global Outcomes guideline advises iron supplements if ferritin is below 500 microgram/L and the transferrin saturation is less than $30 \%$. $^{13}$

An elevated plasma concentration of the soluble transferrin receptor is another useful biochemical marker for iron deficiency which can be used to distinguish it from anaemia of chronic disease. However, there is currently no Medicare rebate for this test. The gold standard for the diagnosis of iron deficiency is a bone marrow biopsy, but this is not commonly used. ${ }^{14}$

\section{Correction of iron deficiency}

The goal of treatment is to replenish iron stores and improve symptoms. Management initially should involve dietary counselling and oral supplements. The evidence regarding the benefit of iron replacement in non-anaemic iron deficiency is based on several small trials and observational studies, mainly in women of reproductive age and patients with heart failure (Table 3). 5,10,12,15-19

The treatment of non-anaemic iron deficiency is similar to the treatment of iron deficiency anaemia. The underlying aetiology must be identified and if possible corrected.

Optimising nutritional iron intake can be achieved by integrating dietary haem iron and free iron. Haem iron (liver, red meat, seafood, poultry) has a superior gastrointestinal uptake compared to free iron (plantbased). Vegetarians can maintain adequate iron intake if a wide variety of non-haem iron is consumed in foods such as wholegrains, legumes, nuts, seeds, dried fruits and green leafy vegetables, but these strategies are unlikely to be sufficient to correct 


\section{Table 3 Benefit of correcting iron deficiency, $5,10,12,15-19$}

\begin{tabular}{|c|c|}
\hline Condition & Evidence \\
\hline $\begin{array}{l}\text { Fatigue and neurocognitive } \\
\text { dysfunction }\end{array}$ & $\begin{array}{l}\text { Improves fatigue in some studies but impact on neurocognitive dysfunction } \\
\text { is uncertain }{ }^{15}\end{array}$ \\
\hline Fibromyalgia & $\begin{array}{l}\text { Improves symptoms of fibromyalgia, possibly related to the role of iron as a cofactor } \\
\text { in neurotransmitter synthesis }{ }^{16}\end{array}$ \\
\hline Restless legs & $\begin{array}{l}\text { Small, randomised trials have shown improved symptoms with iron supplementation } \\
\text { if the serum ferritin is } \leq 75 \text { microgram } / L^{17}\end{array}$ \\
\hline Thyroid disease & $\begin{array}{l}\text { Case reports describe correction of iron deficiency improving persistent symptoms in } \\
\text { patients treated for hypothyroidism with adequate levothyroxine therapy }{ }^{5}\end{array}$ \\
\hline Heart failure & $\begin{array}{l}\text { Several randomised clinical trials in patients who have heart failure with reduced } \\
\text { ejection fraction and iron deficiency have reported improvements in symptoms and } \\
\text { quality of life after intravenous iron therapy }{ }^{12}\end{array}$ \\
\hline $\begin{array}{l}\text { Chronic kidney disease } \\
\text { (haemodialysis) }\end{array}$ & $\begin{array}{l}\text { Intravenous iron in patients with ferritin }<700 \text { microgram/L and transferrin saturation } \\
<40 \% \text { results in less need for erythropoiesis-stimulating drugs, possible cardiovascular } \\
\text { benefits and reduced blood transfusion requirements }{ }^{18}\end{array}$ \\
\hline $\begin{array}{l}\text { Inflammatory bowel } \\
\text { disease }\end{array}$ & $\begin{array}{l}\text { Correction of non-anaemic iron deficiency in patients with inflammatory bowel disease } \\
\text { may improve quality of life }{ }^{19}\end{array}$ \\
\hline Pregnancy & $\begin{array}{l}\text { Iron deficiency should be corrected before and during pregnancy to prevent impaired } \\
\text { neurocognitive function (poor memory and slower neural processing) in the child }{ }^{10}\end{array}$ \\
\hline
\end{tabular}

iron deficiency. Inhibitors of iron absorption (tea, coffee, cocoa, and red wines) should be avoided. This strategy is appropriate for asymptomatic patients who are not at risk of poor absorption.

\section{Iron supplements}

Oral iron therapy is the first-line and safest treatment for symptomatic patients or patients at risk of developing anaemia. It is convenient and cost effective. A number of different iron supplements are available in Australia, however, ferrous salts (fumarate, sulphate, gluconate) are preferred as they are the best absorbed. Guidelines recommend that patients should be counselled to take their iron supplements one hour before or two hours after food. Sometimes it may be possible to compromise on the timing of the dose if this helps the patient adhere to therapy. To improve tolerability, increase adherence to therapy and improve absorption, alternate-day dosing (60-200 mg, depending on tolerability) is superior to daily dosing. ${ }^{20}$

While there are several advantages of oral supplementation, gastrointestinal adverse effects such as nausea, epigastric pain and diarrhoea reduce adherence. Controlled-release preparations and iron polymaltose complex are reported to have a lower incidence of gastrointestinal adverse effects, however, the iron polymaltose complex is expensive which limits its use..$^{21,22}$
Vitamin C co-administration has long been recommended to improve oral iron absorption. However, a recent study reported no significant between-group difference for the mean change in serum ferritin at eight weeks. ${ }^{23}$

If parenteral iron supplementation is required, intravenous iron is indicated. There is no role for intramuscular therapy. The intravenous preparations available are ferric carboxymaltose, ferric derisomaltose, iron polymaltose and iron sucrose. The use of intravenous iron should be limited because of its adverse effects, including permanent skin staining, ${ }^{24}$ hypophosphataemia and rarely anaphylaxis. ${ }^{25,26}$ Intravenous iron should be avoided if there is active systemic infection to avoid any possibility that iron may promote microbial growth and disrupt immune responses. The main indications for intravenous iron include:

- unsuccessful oral therapy - failure, poor adherence, intolerance

- malabsorption (e.g. coeliac disease, bariatric surgery)

- inflammatory bowel disease

- chronic kidney disease receiving erythropoiesisstimulating drugs

- $\quad$ rapid increase in iron required (e.g. pre-operatively for urgent surgery or following acute blood loss)

- $\quad$ heart failure. 


\section{SELF-TEST}

\section{QUESTIONS}

True or false?

1. Iron deficiency requires further assessment to determine the cause even if there is no anaemia.

2. Giving oral iron on alternate days increases adherence to treatment.

3. When parenteral iron is indicated, intravenous iron is preferred over intramuscular iron.

Answers on page 209

\section{Follow-up}

After oral supplements have been taken for 60-90 days, fasting iron studies are repeated one week after stopping therapy to check if the iron deficiency has been corrected. Serum iron has a diurnal variation and the ideal specimen is a fasting morning sample after oral iron supplementation has been withheld for at least 24 hours before testing. If repletion has not occurred, re-investigation is recommended. Iron studies should be repeated approximately 60-90 days, or as clinically appropriate, after intravenous iron therapy. If there is no response to oral iron therapy or if iron deficiency recurs, further investigations should be considered to exclude blood loss or malabsorption. A fall in haemoglobin concentration may be significant even if the patient does not become anaemic. Depending on the clinical findings, referral to a gynaecologist or a gastroenterologist may be appropriate. ${ }^{27}$

\section{Conclusion}

The correction of iron deficiency before the development of anaemia may improve symptoms and the patient's quality of life, but the supporting evidence is variable. Management of iron deficiency requires identification and investigation. For uncomplicated iron deficiency, oral iron is readily available, effective, safe, convenient and cost effective. For those patients intolerant of oral iron or with conditions where oral iron is likely to be ineffective or harmful, the intravenous route is preferred. $\varangle$

\section{Conflict of interest: none declared}

\section{REFERENCES}

1. Lopez A, Cacoub P, Macdougall IC, Peyrin-Biroulet L. Iron deficiency anaemia. Lancet 2016;387:907-16. https://doi.org/10.1016/S0140-6736(15)60865-0

2. Pasricha SR, Flecknoe-Brown SC, Allen KJ, Gibson PR, McMahon LP, Olynyk JK, et al. Diagnosis and management of iron deficiency anaemia: a clinical update. Med J Aust 2010;193:525-32. https://doi.org/10.5694/j.1326-5377.2010.tb04038.x

3. Hopkins RM, Gracey MS, Hobbs RP, Spargo RM, Yates M, Thompson RC. The prevalence of hookworm infection, iron deficiency and anaemia in an aboriginal community in north-west Australia. Med J Aust 1997:166:241-4 https://doi.org/10.5694/j.1326-5377.1997.tb140103.x

4. Ioannou GN, Rockey DC, Bryson CL, Weiss NS. Iron deficiency and gastrointestinal malignancy: a population-based cohort study. Am J Med 2002;113:276-80. https://doi.org/10.1016/S0002-9343(02)01214-7

5. Soppi ET. Iron deficiency without anemia - a clinical challenge. Clin Case Rep 2018;6:1082-6. https://doi.org/10.1002/ccr3.1529

6. Sawada T, Konomi A, Yokoi K. Iron deficiency without anemia is associated with anger and fatigue in young Japanese women. Biol Trace Elem Res 2014;159:22-31. https://doi.org/10.1007/s12011-014-9963-1

7. Ortancil O, Sanli A, Eryuksel R, Basaran A, Ankarali H. Association between serum ferritin level and fibromyalgia syndrome. Eur J Clin Nutr 2010;64:308-12. https://doi.org/10.1038/ejcn.2009.149

8. Zhu XY, Wu TT, Wang HM, Li X, Ni LY, Chen TJ, et al. Correlates of non-anemic iron deficiency in restless legs syndrome. Front Neurol 2020;11:298. https://doi.org/10.3389/fneur.2020.00298

9. Soppi ET. Iron deficiency is the main cause of symptom persistence in patients treated for hypothyroidism. Thyroid 2015;25(Suppl 1):A-74. https://doi.org/ 10.1089/thy.2015.29004.abstracts

10. Benson CS, Shah A, Frise MC, Frise CJ. Iron deficiency anaemia in pregnancy: a contemporary review. Obstet Med 2021;14:67-76. https://doi.org/10.1177/ $1753495 \times 20932426$

11. Dignass A, Farrag K, Stein J. Limitations of serum ferritin in diagnosing iron deficiency in inflammatory conditions. Int J Chronic Dis 2018;2018:9394060. https://doi.org/10.1155/2018/9394060

12. Kocyigit D, Gürses KM. Iron deficiency and its treatment in heart failure: indication and effects on prognosis. E-Journal Cardiol Pract 2016;14. https://www.escardio.org/Journals/E-Journal-of-Cardiology-Practice/ Volume-14/Iron-deficiency-and-its-treatment-in-heart-failure-indications-andeffect-on-prognosis [cited 2021 Sep 30]

13. Ning S, Zeller MP. Management of iron deficiency. Hematology (Am Soc Hematol Educ Program) 2019;2019:315-22. https://doi.org/10.1182/ hematology.2019000034

14. Royal College of Pathologists of Australasia. Soluble transferrin receptor. 2019 https://www.rcpa.edu.au/Manuals/RCPA-Manual/Pathology-Tests/S/Solubletransferrin-receptor [cited 2021 Sep 30]
15. Sharma R, Koch TL, O’Brien SH. Effect of intravenous iron therapy on quality of life in non-anemic iron-deficient young women with fatigue. Blood 2014;124:4858. https://doi.org/10.1182/blood.V124.21.4858.4858

16. Boomershine CS, Koch TA, Morris D. A blinded, randomised, placebocontrolled study to investigate the efficacy and safety of ferric carboxymaltose in iron-deficient patients with fibromyalgia. Rheumatol Ther 2018;5:271-81. https://doi.org/10.1007/s40744-017-0088-9

17. Trotti LM, Becker LA. Iron for the treatment of restless legs syndrome. Cochrane Database Syst Rev 2019:CD007834. https://doi.org/10.1002/ 14651858.CD007834.pub3

18. Macdougall IC, White $C$, Anker S, et al. Intravenous iron in patients undergoing maintenance haemodialysis. https://doi.org/10.1056/NEJMoa1810742

19. Çekiç C, Ijpek S, Aslan F, Akpınar Z, Arabul M, Topal F, et al. The effect of intravenous iron treatment on quality of life in inflammatory bowel disease patients with nonanemic iron deficiency. Gastroenterol Res Pract 2015;2015:582163. https://doi.org/10.1155/2015/582163

20. Stoffel NU, Zeder C, Brittenham GM, Moretti D, Zimmermann MB. Iron absorption from supplements is greater with alternate day than with consecutive day dosing in iron-deficient anemic women. Haematologica 2020;105:1232-9. https://doi.org/10.3324/haematol.2019.220830

21. Santiago P. Ferrous versus ferric oral iron formulations for the treatment of iron deficiency: a clinical overview. ScientificWorld Journal 2012;2012:846824. https://doi.org/10.1100/2012/846824

22. Geisser P. Safety and efficacy of iron(III)-hydroxide polymaltose complex / a review of over 25 years experience. Arzneimittelforschung 2007;57 6A:43952. https://doi.org/10.1055/s-0031-1296693

23. Li N, Zhao G, Wu W, Zhang M, Liu W, Chen Q, et al. The efficacy and safety of vitamin $C$ for iron supplementation in adult patients with iron supplementation in adult patients with iron deficiency anaemia: a randomized clinical trial. JAMA Netw Open 2020;3:e2023644. https://doi.org/10.1001/ jamanetworkopen.2020.23644

24. Canning M, Grannell L. A stain on iron therapy. Aust Prescr 2020;43:160-3. https://doi.org/10.18773/austprescr.2020.051

25. National Blood Authority. Iron product choice and dose calculation guide for adults: guidance for Australian health providers. Canberra: National Blood Authority; 2015. https://www.blood.gov.au/iron-product-choice-and-dosecalculation-guide-adults [cited 2021 Sep 30]

26. Shand AW, Bell J, Henry A, Grzeskowiak LE, Kidson-Gerber G, Pearson S, et al. Rapid increase in intravenous iron therapy for women of reproductive age in Australia. Med J Aust 2020;213:85-6. https://doi.org/10.5694/mja2.50618

27. Gastroenterological Society of Australia. Clinical update: Iron deficiency Melbourne: GESA; 2015. https://www.gesa.org.au/education/clinicalinformation [cited 2021 Sep 30]

\section{FURTHER READING}

Ems T, St Lucia K, Huecker MR. Biochemistry, iron absorption. Treasure Island (FL): StatPearls Publishing. Last updated 2021 Apr 26. https://www.ncbi.nlm.nih.gov/ books/NBK448204 